\title{
REMOTE SENSING APPLICATIONS TO HYDROLOGICAL MODELING
}

\author{
C. OTTLE ${ }^{1}$, D. VIDAL-MADJAR ${ }^{1}$ and G. GIRARD ${ }^{2}$ \\ ${ }^{1}$ CNET-CNRS/CRPE, s\$1 40 Rue du Général Leclerc, 92131 Issy-les-Moulineaux (France) \\ ${ }^{2}$ ENSMP/CIG, 35 Rue St. Honoré, 77305 Fontainebleau (France)
}

(Received December 8, 1987; revised and accepted February 22, 1988)

\section{ABSTRAC1}

Ottlé, C., Vidal-Madjar, D. and Girard, G., 1989. Remote sensing applications to hyd ological modeling. J. Hydrol., 105: 369-384.

Surface temperature estimated from thermal infrared measurements may be used to derive real evaporation and soil moisture which are of great importance to hydrologists for the monitoring of the hydraulic budgets of soils. But, in order to introduce the surface temperatures into the hydrological models, the surface parameterizations must be changed.

Presented here is how an hydrological model has been modified to simulate both the hydraulic and energy budgets at the soil surface.

The simulated water budgets are finally compared to the water deficit observed from space through infrared satellite data.

\section{INTRODUCTION}

Remote sensing data from satellites can provide much useful information for hydrological modeling. These applications fall into different arcas. Satellite data cari be used first, to improve the definition of soile and land covers cier the watershed, which determines infiltration, evapotranspiration and runcoff coefficients. Secondly, because remote sensing measures spatial information rather than point data, it can help to correct errors on imput parameters (iike precipitation or real evaporation), resulting from point measurements. But the most important information given by remote sensing techniques for hydrologists is the estimation of soil moisture and evapotranspiration that can be derived from sat models to monitor water exchanges between the soil laver and the atmosphere (Engman, 1986).

As a matter of fact, this is possible now with infrared radiometric measurements and it has been shown (Carlson, 1985; Taconet et al., 1986a), that surface soil moisture in the case of bare soils and soil water content ir the root zone under dense vegetation can be obtained through the energy balance at the land-atmosphere interface, provided the atmospheric forces and the physical 
and biological behaviour of the surface are known. With a modeling of the hydraulic and energy budgets, surface temperature measured around its rnaximum daily value is sufficient to derive areal evapotranspiration and the global surface resistance to evaporation from wich soil water content can be estimated. This methodology has been developed with a two-layer model simulating heat and hydraulic budgets derived from Deardorff (1978) and validated over bare soils (Soares et al., 1987) and over dense vegetation (Taconet et al., 1986b).

To allow hydrological models to simulate the different components of surface energy balance, soil parameterizations must be changed. The principal objective of this paper is to show how we have modified the surface layer parameterization of an hydrological model to derive evaporation and soil water content and prepared the use of radiometric measurements.

The first results on the comparison of the two parameterizations on

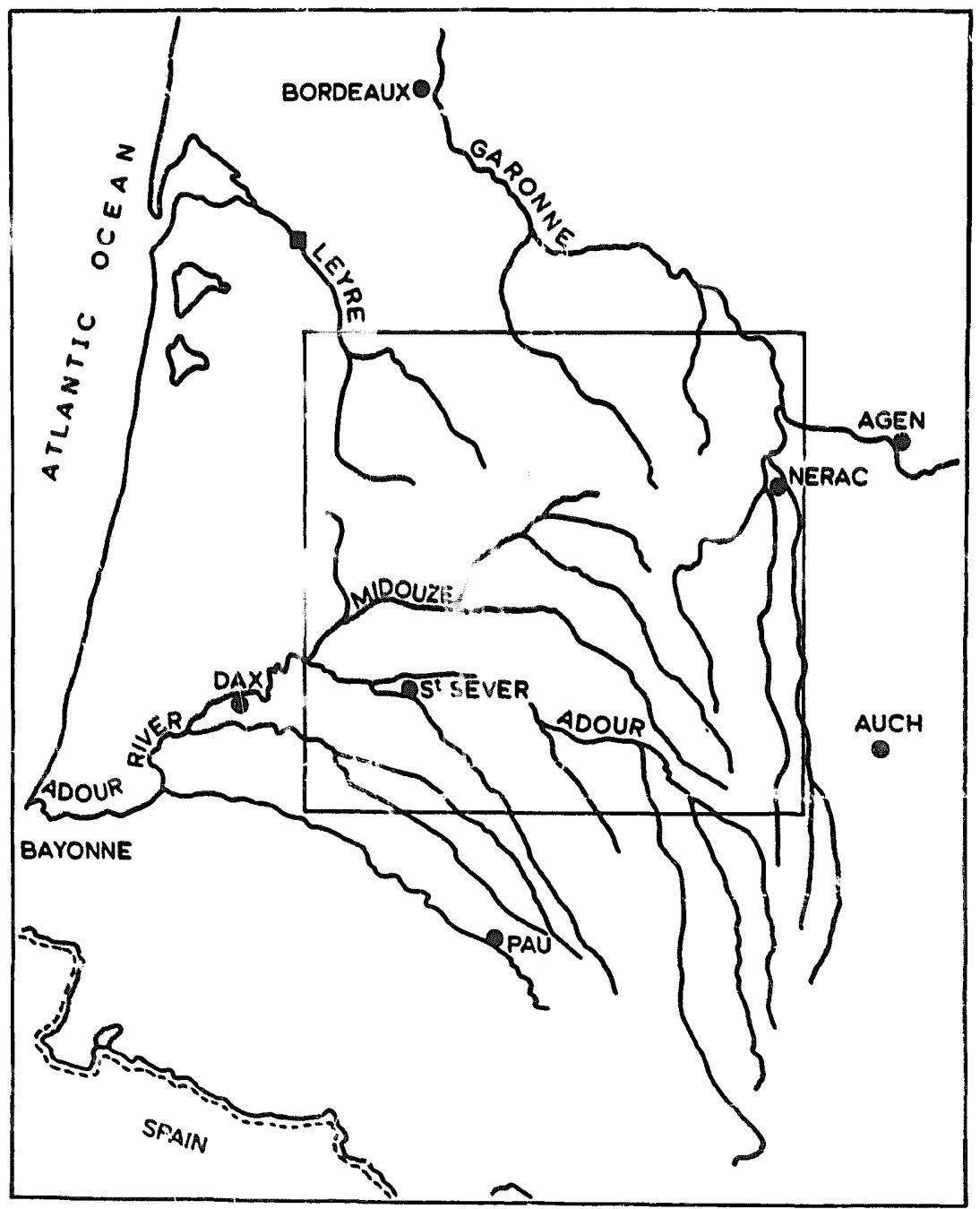

Fig. 1. Adour River system over the region under study. 
simulations of the streamflows over the HAPEX-MOBILHY experiment site (André et al., 1986) in south-western France during the year 1985, are presented.

In a first part, the hydrological model and the watershed under study are described. Then the two models are presented and compared, especially during summer months where they act differently. Finally, a comparison is made with water deficit maps derived from satellite observations.

\section{SITE DESCRIPTION}

The studied area is the one of the HAPEX-MOBILHY experiment. The HAPEX program (André et al., 1987), has been developed to study the hydrological budget and the surface fluxes, especially evaporation, at a scale compatible with the mesh of general circulation models, i.e. of the order of $10^{4} \mathrm{~km}^{2}$. An area of $100 \times 100 \mathrm{~km}^{2}$ has been chosen in south-western France. The site is relatively variable in vegetative or topographic fields. The "Landes" forest (in the northwestern part of the square) with flat and sandy soils is clearly distinct from the mixed-crop zones. In the hydrological field, the region is watered by the Adour river, and its tributaries are well developed as shown by Fig. 1. On this area, different measurement networks (Fig. 2) were set up to

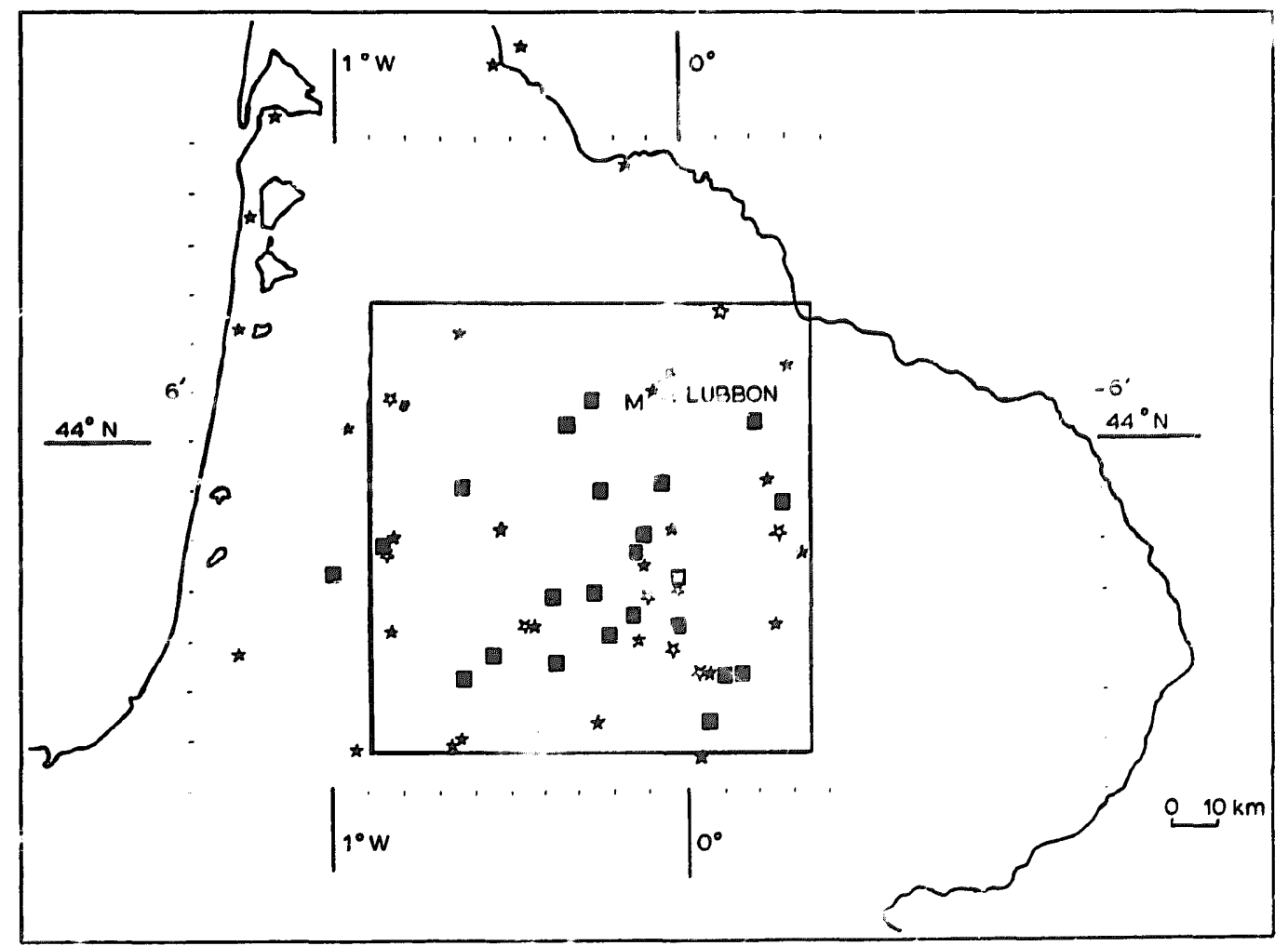

Fig. 2. Site chosen for the HAPEX-MOBILHY experiment in southwestern France with loration of the central site and of the surface ne $\%$ r.rks. Full star = PATAC stations; open star = SAMER stations associated with neutron sounding; ope: square = neutron sounding station; fuli square $=$ stream gauging station; $M=$ iforest mast) 
provide surface energy budget, hydrological budget and meteorological parameters on a yearly basis. These measurements have been made from April 1985 (for surface hydrology and upper soil moisture content) or May 1986 (for surface energy budget and surface heat fluxes) until mid-January 1987.

In the hydrological field, in addition to the permanent equipment, which consists of 33 streamflow gauges and 59 raingauge stations, neutronic soundings have been set up in ten different characteristic locations over the square to measure soil humidity from the surface to $1.5 \mathrm{~m}$ in layers of $10 \mathrm{~cm}$. To model the streamflows over the Adour watershed, an hydrological model (Girard, 1974; Ledoux, 1980) has been implemented for the region.

\section{MODEL DESCRIPTION}

This simulation model is a multilayer mass balance-type model which takes rainfall as input and calculates storage and runoff in the surface layer and infiltration to the underground. As nearly $90 \%$ of the underground flows for this watershed takes place in the first aquifer, the model has been simplified and calculates the streamflows in only two layers: the surface layer which represents the first meter of soil, and the underground. These two domains have been discretized on a grid-square of $5 \mathrm{~km}$ but the meshes are sometimes divided in two or four parts in the regions where the exchanges between the surface and the underground must be more precisely described (Fig. 3), especially near the rivers.

We can notice that the model domains expand beyond the HAPEX square to take into account the whole watershed. In that way, ten outlets have been definer which correspond to ten small watersheds, and the streamflows in the superficial layer are calculated for each individually (Girard and Boukerma, 1985).

Soil types and vegetation hav been determined with survey maps. As vegetal cover and soil constitutios are closely tied (for example, sandy soils are generally covered by forested area ), only nine zones corresponding to the most important geological and pedologeal structures have been kept (Fig. 4). Then, a percentage of each of these soil types is assigned to each mesh.

The model simulates the wate transports in the two domains by three mechanisms. A first scheme called "production" deals with the surface layer and divides the rainfall in storage, infiltration, surface runoff and evaporation depending on soil coefficients. A second one calculates the surface transport, routing the runoff from each gridpoint to the closet rivermesh according to drainage directions defined from topographic maps. Finally, a last routine calculates the infiltration to the water tables, the transport in the underground and aiso the water fluxes from the ground to the surface which are allowed only in the river meshes. As the model is designed for dr:ade time periods, the coinputation time step has been set to one day.

To allow the simulation of the energy balance at the surface and then a comparison with the water stress derived from satellite data, the production 


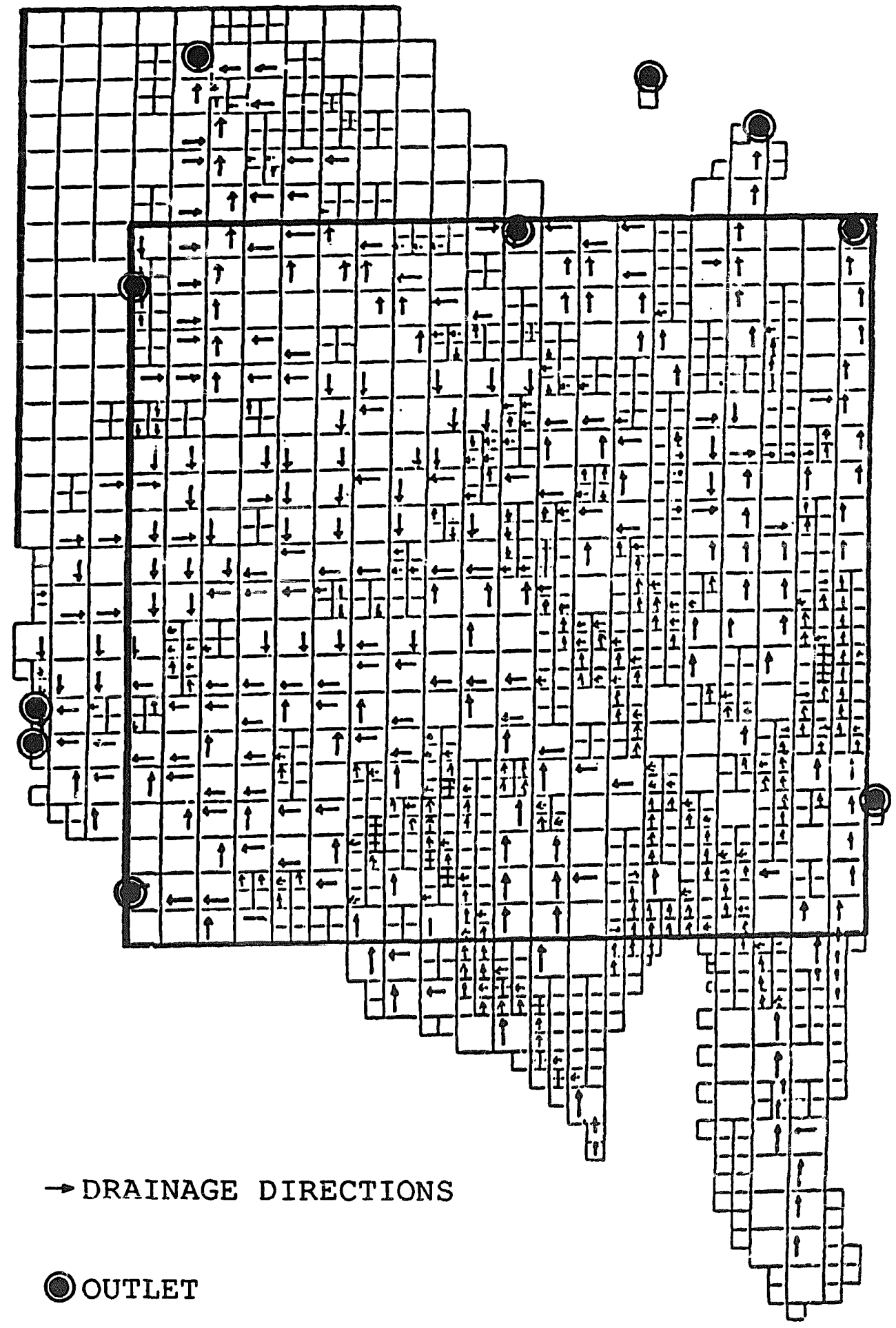

Fig. 3. Spatial discretization of the superficial domain. The river meshes and the outlets of the w'atershed are pointed out. 


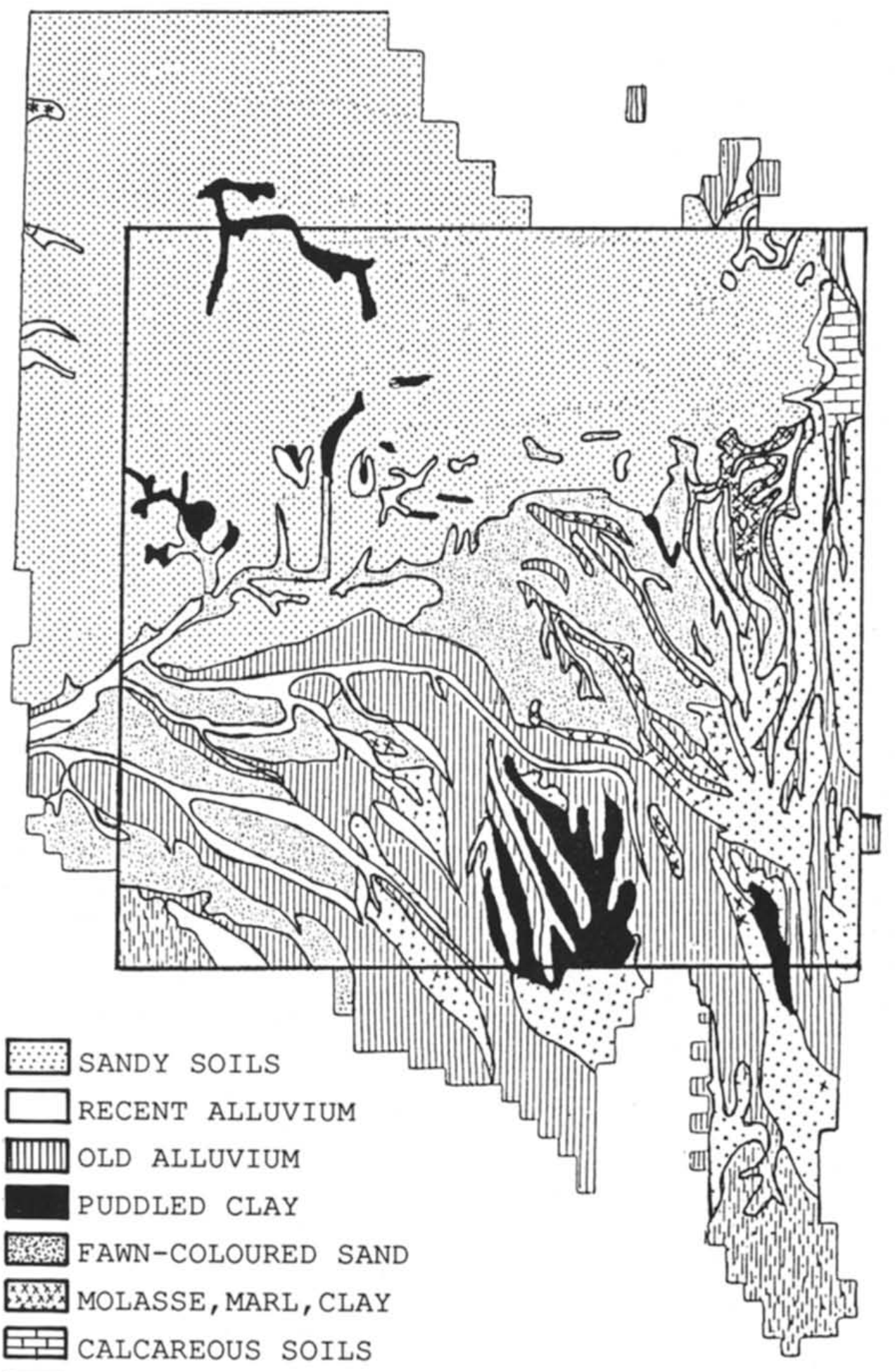

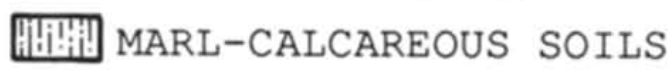

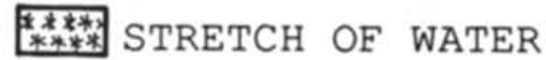

Fig. 4. Soil classification of the model's grid. 


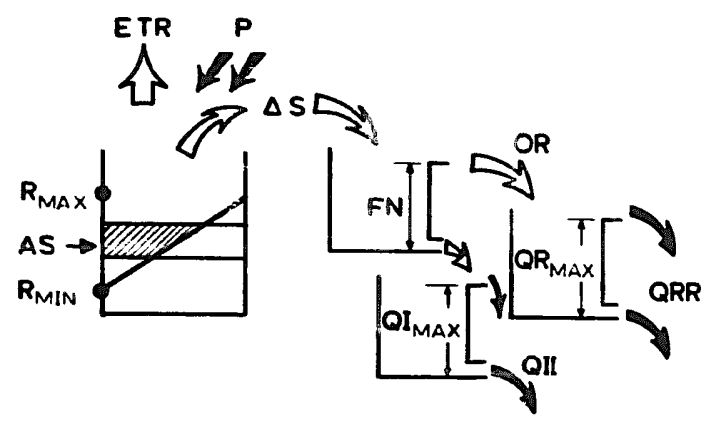

Fig. 5. Surface parameterization of the hydrological model from Girard (1974). QII = infiltration; QRR = runoff.

scheme which describes the exchanges between the soil and the atmosphere has been changed in a new parameter $\bar{u}_{a}$ ion derived from Deardorff (1977).

\section{PARAMETERIZATION OF THE SURFACE-LAYER WATER BUDGET}

The parameterization of Girard (1974) considers the surface layer as a bulk layer $1 \mathrm{~m}$ deep. The hycirological budget is calculated at each time step of the model (1 day), according to precipitation, potential evaporation and to the initial state of the reserve. The quantity of water which will be stored in the surface layer depends on two parameters representing the minimum and the maximum levels of the reservoir $\left(R_{\min }\right.$ and $R_{\max }$, see Fig. 5). The remaining water is then shared between infiltration and runoff, depending on an infiltration threshold value set for each type of soils. Two more reservoirs have been introduced to calculate delayed infiltration and runoff.

All these parameters have been adjusted for each type of soil in order that the simulated flows repr $h$ ace the observations at the outlets. This calibration has been done using nine years of data.

This parameterization is sufficient for hydrologists who are interested in simuluting mean flows at the outlets or who want to understand global or crude properties of a watershed. But if one wants to iollow the hydraulic state of the

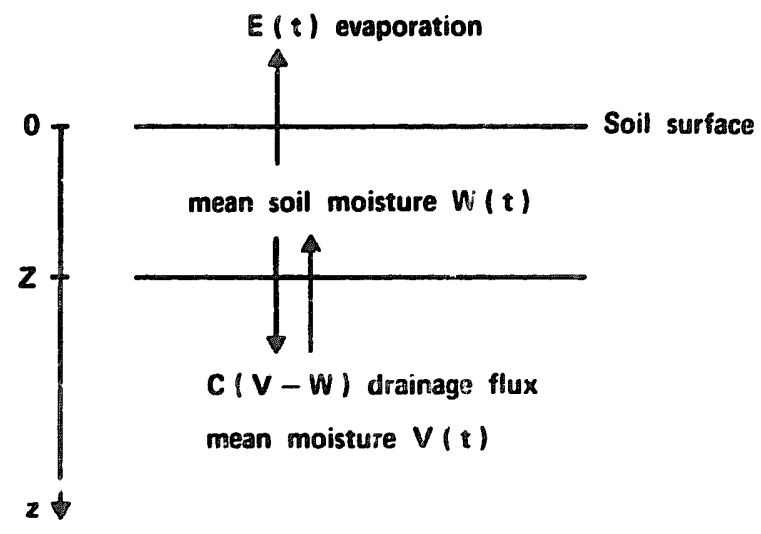

Fig. 6. Surface parameterization introduced in the hydrologica: model from Betnard et al. (198\%). 
surface for irrigation purposes for instance, or to monitor soil moisture or real evapotranspiration, this scheme is not sufficient, especially for long-time simulations where, even if the model is well initialized, the error on the output increases with time. For those applications, it is then necessary to be able to reinitialize regularly the model with new data which may be derived from thermal infrared satellite images.

On the other hand, for our purpose, which is the simulation of the energy and water budgets at the surface, a more precise description of the soil layer is needed, which allows differentiation between the very superficial soil layer (the first centimeters of soil) and the bulk layer.

For this reason, the surface scheme has been changed in a parameterization derived from Deardorff (1977) and proposed by Bernard et al. (1986). The soil is now represented by two layers, a very superficial layer (about $10 \mathrm{~cm}$ ) and a bulk layer $1.20 \mathrm{~m}$ deep, and the water contents of these two reservoirs are calculated by a force restore method (Fig. 6).

If $W_{2}$ is the soil moisture of th bulk layer and $W_{1}$, the humidity of the superficial layer, their evolution is given by the following equations:

$$
\begin{aligned}
& \frac{\delta W_{1}}{\delta t}=\frac{(P-E)}{a_{1}}+C\left(W_{2}-W_{1}\right) \\
& \frac{\delta W_{2}}{\delta t}=\frac{(P-E)}{d_{2}}
\end{aligned}
$$

where $d_{1}=0.1 \mathrm{~m}$ and $d_{2}=1.2 \mathrm{~m}$ which are respectively the height of the two layers of water content $W_{1}$ and $W_{2}, E$ is evaporation, $P$ is precipitation and $C$ is a pseudo-diffusivity and its unit is $\mathrm{T}^{-1}$. It is a function of $d_{1}$ and $d_{2}$ and of the soil hydraulic state represented by $W_{1}$ and $W_{2}$.

The partition of the water between runoff and infiltration depends on the properties of the soil but also strongly on the nature of the vegetation cover. For example, precipitation infiltrates more over vegetated areas than over bare soils. To take into account this effect in the model, runoff is calculated in the following way: over bare soils, runoff appears as soon as the first layer is saturated, while over vegetated areas, it only starts when the bulk layer is filled up. The remaining water is infilt rated according to the infiltration rate defined by the former scheme.

For the calculation of the evapotranspiration, it is clear that real evaporation is lower than potential evaporation and that the properties of the vegetation cover must be described precisely. But in a first step, to simplify the problem, the real evapcration has been reduced from potential evaporation, by a factor " $\beta$ ", depending on the soil water content of the bulk layer, following the parameterization of Manabé (1969):

$$
\begin{aligned}
& E=\beta \times E T P \\
& \beta=\min \left(1,3 \times W_{2} / W_{2 \max }\right)
\end{aligned}
$$

ETP is the potential evaporation and $W_{2 \max }$ is the saturation value of the bulk layer. 
First, a calibration las been done on the soil parameters (maximum soil capacities of the two layers, soil hydraulic conductivity, infiltration rates) to restore the same monthly runoff and infiltration as the first model, already adjusted to the measurements made at the different outlets of the watershed. It has been done for the years 1984-1985, for which the meteorological and hydrological data (potential evaporation, precipitation, streamflows and piezometric data) were available. Hereafter, this model will be called "model B", whereas the first model with Girard's parameterization will be called "model A".

\section{RESULTS}

These two simulations show that although infiltration and runoff are the same on a monthly basis, due to the calibration procedure, surface layer behaviour can be very different especially in the summer. One drawback of Girard's parameterization is that, as long as there is some water left in the soil, it is evaporated at the potential rate. So as early as the beginning of surimer, the model simulates the following situction: the upper reservoir is already at its minimum level and all the precipitation is immediately re-evaporated.

The second parameterization simulates a much more realistic situation: the evaporation is limited as soon as the soil begins to dry and has more regular variations. This is clearly shown in Fig. 7, where the evaporation simulated by the two models during the surmmer 1985, averaged over a region of $10 \times 10 \mathrm{~km}^{2}$ in the south-western part of the HAPEX square is plotted. On the other hand, because there is no minimum level for the reservoir (except 0 ), the amplitude of variation for soil moisture is greater and the drying of soils is more graduai. Figure 8 shows the variation of the bulk-layer relative humidity, simulated by the two models during summer 1985 and the raeasurements of a neutronic probe set tup in the same location. The results of the second model are in very good agreement with the measuremesis (the variation and the values are realistic). Soils dryed up until the end of Septemiver (which was especially dry in 1985)

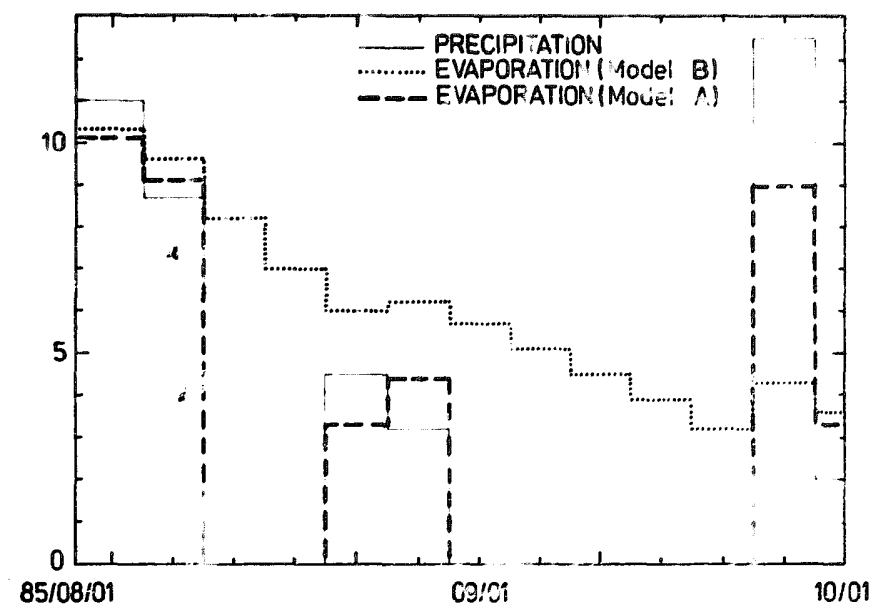

Fig. 7. Evaporation simulated with the two parameterizations (values are in mm, cumulated over 5-day periods?. 
SOIL HUMIDITY

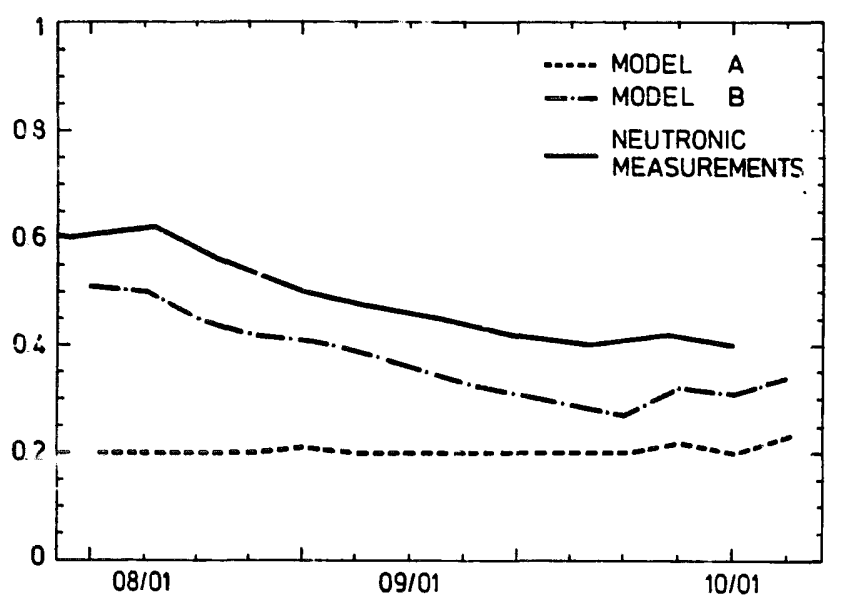

Fig. 8. Comparison of the soil humidity simulated with the two parameterizations to the neutronic measurements.

whereas with the first model (Girard's parameterization) the minimum value is already reached at the end of July, and evaporation can occur only after precipitation.

For a further validation of this new parameterization, the results of the two simulations have been compared to the water deficit observed by satellite.

As a matter of fact, canopy temperature has long been recognised as an indicator of water availability. When the soil begins to dry, the plant reduces its evaporation to avoid drying out, and consequently leaf temperature increases.

Then, if one can follow this temperature day after day, measured always at the same time (e.g., around the maximum heating), it may be an indicator of stress.

Different indices to quantify plant water stress have been proposed, using canopy temperature measured by infrared radiometry (Jackson et al., 1977, 1981; Boatwright and Whitehead, 1986).

Jackson et al. (1977) particularly proposed to follow the canopy-air temperature difference measured post-noon, called the Stress-Degree-Day (SDD), and found in many cases, a good correlation with soil water requirements.

In a first step, the SDD was computed all over the Hapex square using infrared satellite data to determine surface temperatures, and in-situ air temperature measurements, and compared with the water budget simulated by the two models. We now describe how the SDD has been calculated and the results of :he comparison with the models.

\section{IMAGES PROCESSING}

We have selected cloudless images from NOAA9-AVHRR over southwestern France and treated only Channel $4(10.5-11.3 \mu \mathrm{m})$ to recover surface temperature. 

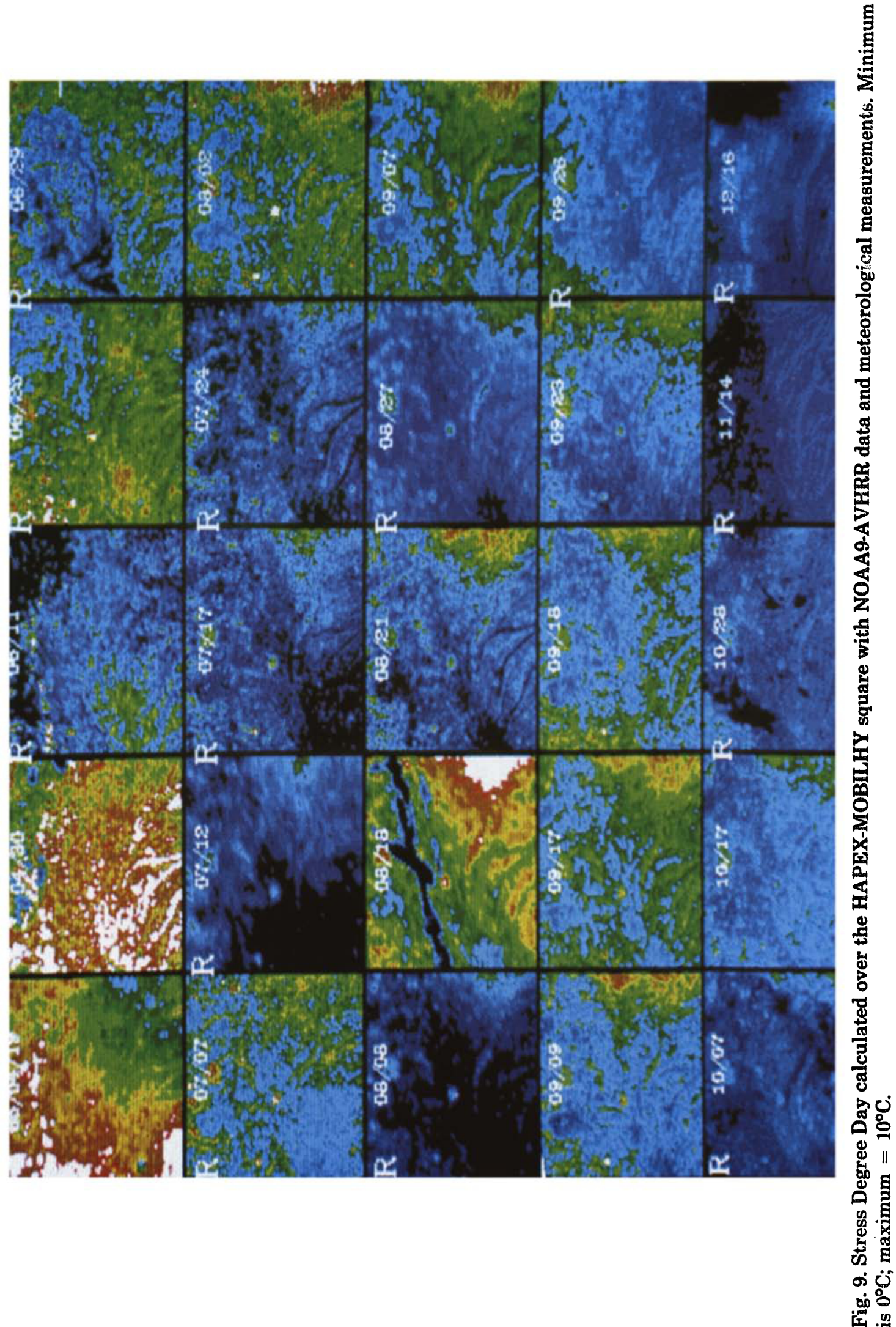
Twenty-eight images chosen betureen April and December 1985 have been processed. The radiometric calibra. $n$ has been done using the coefficients given by the AVHRR on-board calibration. Geographic corrections and resampling was performed which gave rectified images with one point per $\mathrm{km}^{2}$. The final error on the position of characteristic points does not exceed 2 at $3 \mathrm{~km}$.

The experimental zone (HAPEX square: $100 \times 100$ pixels) has been extracted for each of the images, and surface radiances have been corrected from atmospheric absorption using the LOWTRAN4 radiation model (Kneizis et al., 1983), and ineteorological radiosoundings done at midday in Toulouse at the southwest of the Hapex site. To determine surface temperature $T_{s}$ from the thermal radiances, the emissivity of the surface was set to unity.

The air temperature $T_{\mathrm{a}}$ has been linearly interpolated on a $20 \times 20 \mathrm{~km}^{2}$ grid from the PATAC network of the french meteorological office ( 40 stations above the square; see Fig. 1).

The differences $\left(T_{\mathrm{s}}-T_{\mathrm{a}}\right)$ are visualised on Figure 9. The letter " $\mathrm{R}$ " between two images means that precipitation occurred between the two dates. The colour scale ranges from black (for low values of $T_{\mathrm{s}}-T_{\mathrm{a}}$ ) to blue, yellow, red and white. Values greater than $10^{\circ} \mathrm{C}$ are saturated in white.

From these pictures, we can see that high values occur during dry periods or at the beginning of the period (during the month of April, because the soil is essentially bare and heats more quickly than vegetated areas). On the other hand, after a rainy period, the surface is wet, the evaporation can be high and consequently the SDD is much lower. This correlation between the SDD and precipitation is more visible on averages over small regions and on the time evolutions. It is presented here, only for the southwestern part of the square on Fig. 10, and the precipitation is plotted on the same graph. The decrease of $\left(T_{\mathrm{s}}-T_{\mathrm{a}}\right)$ after a rain as well as the increase of the maximum values during the drying period (frum July to September) are clearly seen.

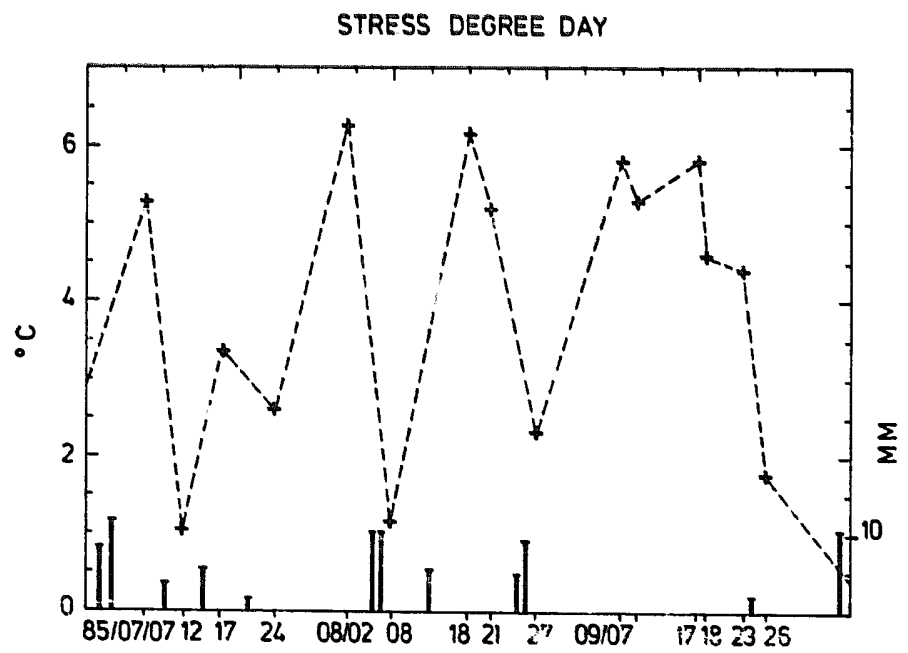

Fig. 10. Time evolution of the Stress Degree Day averaged over the southwestern part of the HAPEX-MOBILHY square. 
From this figure, we can see also that it is not possible to read these data without the knowledge of the atmospheric forcing.

For example, if we compare the 18th and the 21st of August or the 18th and the 23rd of September, the differences are not explained by a variation of the soil water content (no rain occurs between those two dates), but may result from wind speed or net radiation differences. The meteorological measurements showed an increase of the wind on the 21st of August (3 compared to $0.5 \mathrm{~m} \mathrm{~s}^{-1}$ on the 18th), which explains a decrease of the temperature gradient by a larger mixing of the air.

In the same way, the difference between the 18th and the 23rd of September is explained by lower surface temperatures on the $23 \mathrm{rd}$, probably caused by several cloud passings clearly visible on the plotting of the daily net radiation.

Th that the atmospheric forcing like vapor pressure deficit, net radiation and wind should be taken into account in the definition of a water stress index.

For this reason, the Crop Water Stress Index (CWSI) proposed by Jackson et al. (1981), a function of the ratio of "eal evaporation to potential evaporation, is certainly more appropriate because it integrates environmental factors; but it could not be used in this study because it requires radiative measurements above the canopy not available here.

An index which should be close to the CWSI is the ratio of the canopy-air temperature difference to the water vapor pressure deficit, which has been plotted on Fig. 11, averaged over the southwestern part of the Hapex square during summer 1985. The drying at the end of the summer (in September particularly) which appears on the neutron probe data (Fig. 8) and which is predicted by the hydrological model and the resulting canopy stress see'm very well correlated. The stress increases all along the summer until the snd of September (25th), when it falls rapidly, corresponding to the recovery precipitation.

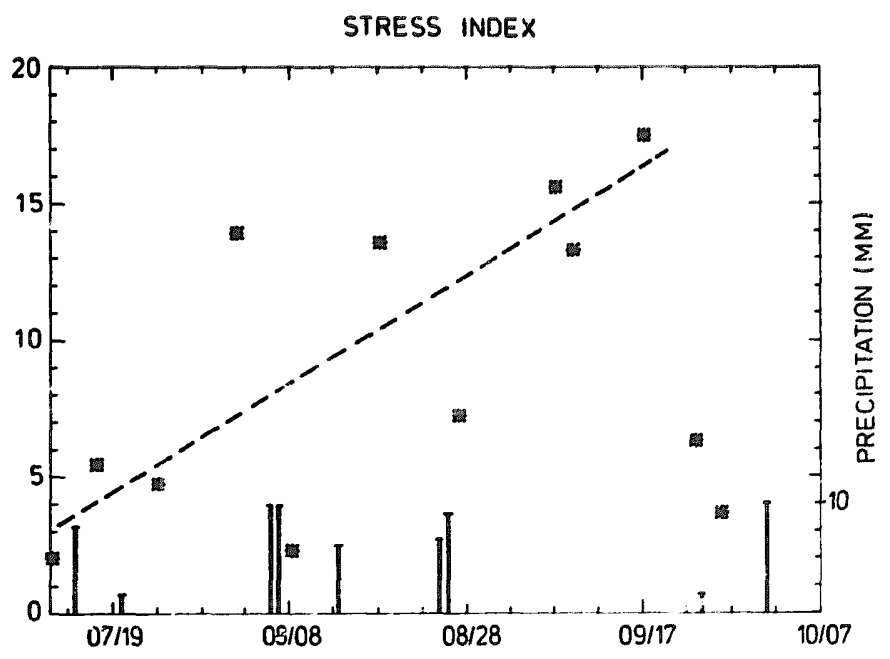

Fig. 11. Stress Index variations during summer 1985. 
SOIL HUMIDITY

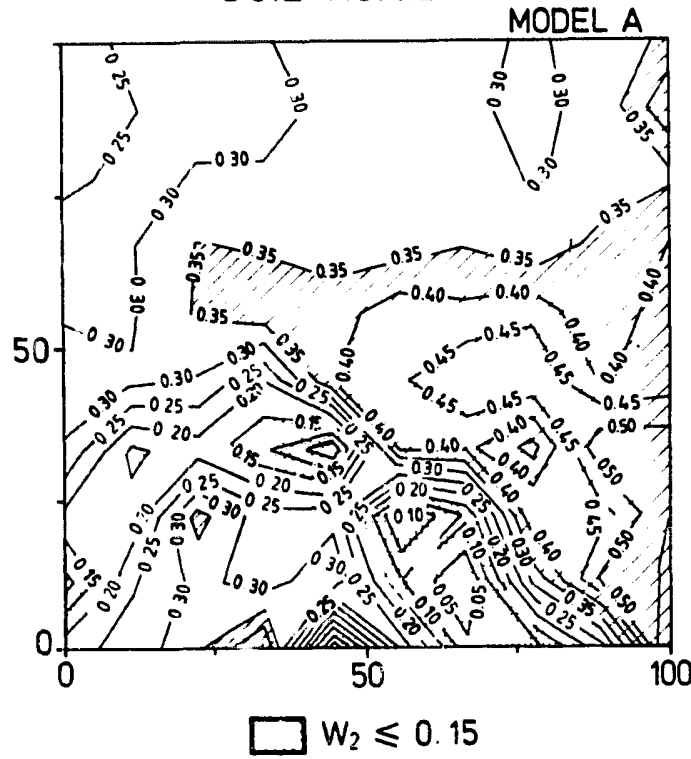

SOIL HUMIDITY

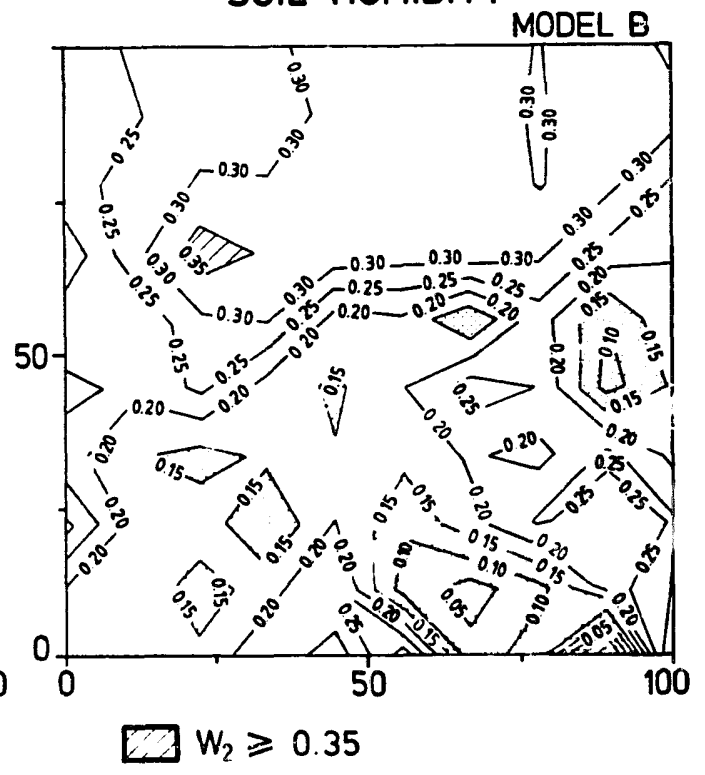

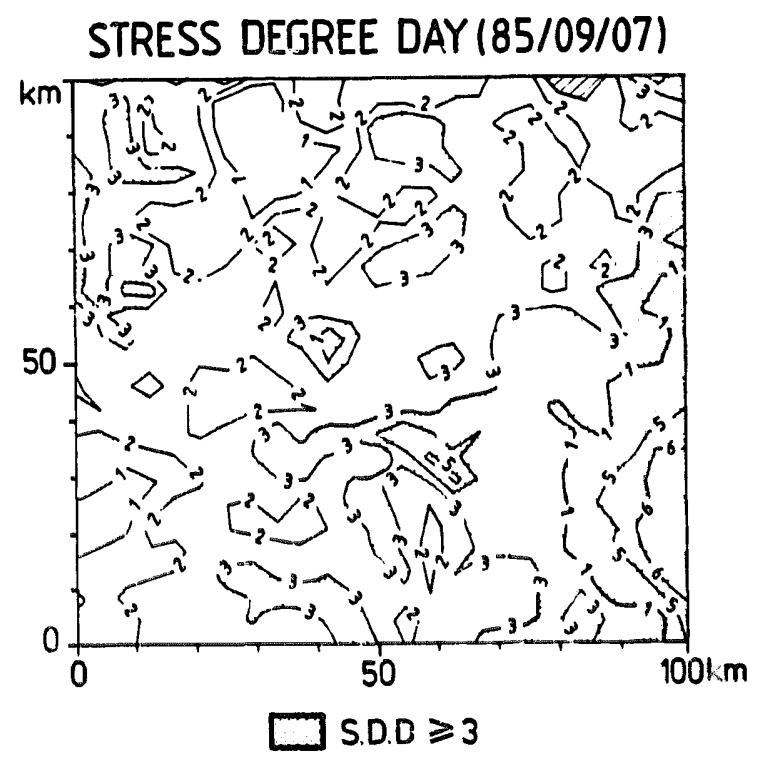

Fig. 12. Comparison of the soil water budget simulated by the two models to the SDD computed with satellite data.

\section{COMPARISON OF THE HYDROLOGICAL MODELS}

Finally, the water content in the surface layer simulated by the model with the two parameterizations has been compared to the Stress Degree Day maps for different dates, and the results for the 7th of September are shown on Fig. 12.

The map of $\left(T_{\mathrm{s}}-T_{\mathrm{a}}\right)$ shows high values in the southeastern part of the square (corresponding to gradients greater than $4^{\circ} \mathrm{C}$ ), which should point out a drying area. If we compare to the soil humidity maps simulated by the two models, we can see that the model of Girard simulates a very humid region (soil 
moisture greater than $40 \%$ and more humid than the "Landes" forest), and that the present model shows a drying area which seems more realistic.

In the same way, with the second model, the gradients between the different zones are lower: the forest in the northern part is clearly delimited with values greater than $30 \%$ from the crop areas in the south, which dry out more rapidly. Generally, it seems that Deardorff's model simulates a distribution of humid and dry areas in better agreement with the distribution of $\left(T_{\mathrm{s}}-T_{\mathrm{a}}\right)$.

\section{CONCLUSIONS}

These preliminary results seem to show that the second model where the surface parameterization derived from Deardorff (1977) has been introduced, simulates a more realistic water budget. The limitation of the evaporation and the introduction of the vegetation for the computation of the runoff have certainly improved the simulation of soil water content, especially during summer months, where Girard's parameterization gives unrealistic results.

It has been shown here that the soil drying during the summer 1985 can be seen on satellite images through stress indexes (increasing of the index during rainless periods) and that the second model simulates a global distribution of soil water content in good agreement with the water deficit maps derived from satellite observations.

Thus it is now possible to simulate both the hydraulic and energy surface budgets, each day satellite NOAA9 images are available to restore the surface resistance to evaporation by inversion of the surface temperature and to obtain consequently, real evapotranspiration and soil water content in the root zone in a way similar to the methodology described by Taconet et al. (1986a).

Then the soil humidity simulated by the model will be reinitialized regularly to correct the errors on the input parameters like rainfall, which is probably the most difficult variable to estimate.

This contribution of remote sensing to hydrological modeling should improve the follow-up of soil humidity especially during drying periods when information on crop conditions are strongly needed for farm management decisions.

\section{ACKNOWLEDGEMENTS}

The authors would like to thank $R$. Bernard and $O$. Taconet for interesting discussions. We wish also to acknowledge the help of C. Tiffon and D. Ho for the image processing and the visualization. This study was supported by the Centre National d'Etudes Spatiales and the Centre National de la Recherche Scientifique in the frame of the HAPEX-MOBILHY program.

\section{REFERENCES}

André, J.C., Goutorbe, J.P. and Perrier, A., 1986. HAPEX-MOBILHY, A Hydrologic Pilot Experiment for the study of water budget and evaporation flux at the climatic scale, Bull. Am. Meteorol. Soc., 67: 138-144. 
André, J.C., Goutorbe, J.P., Perrier, A., et al., 1987. Evaroration over land-surfaces: First results from HAPEX-MOBILHY special observing period. Ann. Geophys., 6(5): 477-492.

Bernard, R., Soarès, J.V. and Vidal-Madjar, D., 1986. Differential bare field drainage properties from airborne microwave observation. Water Resour. Res., 22(6): 869-875.

Boatwright, G.O. and Whitehead, V.S., 1986. Early warning and crop condition assessment research. IEEE Trans. Geosci. Remote Sensing, GE-24(1): 54-64.

Carlson, T.N., 1985. Regional scale estimates of surface moisture availability and thermal inertia using remote thermal measurements. Remote Sensing Rev., 1: 197-247.

Deardorff, J.W., 1977. A parameterization of ground surface moisture content for use in atmospheric prediction models. J. Appl. iMeteorol., 16: 1182-1185.

Deardorff, J.W., 1978. Efficient prediction of ground surface temperature and moisture, with inclusion of a layer of vegetation. J. Geophys. Res., 83(4): 1889-1903.

Engman, E.T., 1986. Hydrologic research before and after AgRISTARS. IEEE Trans. Geosci. Remote Sensing. GE-24: 1: 5-11.

Girard, G., 1974. Modèle global ORSTOM, première application du modèle journalier à discretisation spatiale sur le bassin versant de la crique Grégoire en Guyane. In: Atelier Hydrologique sur les Modèles Mathématiques. ORSTOM, Paris.

Girard, G. and Boukerma, B., 1985. Projet HAPEX-MOBILHY, calage du modèle hydrologique, exploitations spécifiques et propositions d'utilisation. Rapport LHM/RD/85-110, Centre Inf. Géol. (available from C.l.G., 35 rue Saint-Honoré, 77305 Fontainebleau Cédex, France).

Jackson, R.D., Reginato, R.J. and Idso, S.B., 1977. Wheat canopy temperature: A practical tool for evaluating water requirements. Water Resour. Res., 13: 651-656.

Jackson, R.D., Idso, S.B., Reginato, R.J. and Pinter, P.J., Jr, 1981. Canopy temperature as a crop water stress indicator. Water Resour. Res., 17(4): 1133-1138.

Kneizis, F.X.. Shettle, E.P. et al., 1983. Atmospheric Transmittance/Radiance. Computer code LOWTRAN6, Air Force Geophys. Lab., Mass. Rep., AFGL-TR-83-0187.

Ledoux, E., 1980. Modélisation intégrée des écoulements de surface et des écoulements souterrains sur un bassin hydrologique. Thèse de Docteur-Ingénieur, École Natl. Supéreure des Mines de Paris, et Université P. et M. Curie, Paris.

Manabé. S., 1969. The atmospheric circulation and the hydrology of the Earth's surface. Mon. Weather Rev., 97: 739774.

Soarès, J.V., Bernard, R., Taconet, O. Vidal-Madjar, D. and Weill, A., 1987. Estimation of a bare soil evaporation from airborne measurements. J. Hydrol. 99: 281-296.

Taconet, O., Bernard, R. and Vidal-Madjar, D., 1986a. Evaporation over an agricultural region using a surface flux/temperature model based on NOAA/AVHRR data. J. Climatol. Appl. Meteorol., 25: 284-307.

Taconet. O., Carlson, T.N., Bernard, R. and Vidal-Madjar, D., 1986b. Evaluation of a surface vegetation parameterization using satellite measurements of surface temperature J. Climatol. Appl. Meteorol., 25: 1752-1767. 